\title{
Resolution of galactose, glucose, xylose and mannose in sugarcane bagasse employing a voltammetric electronic tongue formed by metals oxy-hydroxide/MWCNT modified electrodes
}

\author{
Acelino Cardoso de Sáa,b,*, Andrea Cipri ${ }^{\mathrm{b}}$, Andreu González-Calabuig ${ }^{\mathrm{b}}$, \\ Nelson Ramos Stradiotto ${ }^{\mathrm{a}}$, Manel del Valle ${ }^{\mathrm{b}, *}$ \\ a Department of Analytical Chemistry, Institute of Chemistry, Universidade Estadual Paulista (UNESP), 55 Rua Francisco Degni, Araraquara 14800-060, SP, \\ Brazil \\ b Sensors and Biosensors Group, Department of Chemistry, Universitat Autònoma de Barcelona, Edifici Cn, 08193 Bellaterra, Barcelona, Spain
}

\section{A R T I C L E I N F O}

\section{Article history:}

Received 4 June 2015

Received in revised form 29 July 2015

Accepted 19 August 2015

Available online 21 August 2015

\section{Keywords:}

Electronic tongue

Carbohydrates

Artificial neural network

Multi-walled carbon nanotubes

Metal nanoparticles

Second generation ethanol

\begin{abstract}
A B S T R A C T
Second generation ethanol is produced from the carbohydrates released from the cell wall of bagasse and straw of sugarcane. The objective of this work is the characterization and application of a voltammetric electronic tongue using an array of glassy carbon electrodes modified with multi-walled carbon nanotubes containing metal (Paladium, Gold, Copper, Nickel and Cobalt) oxy-hydroxide nanoparticles (GCE/MWCNT/MetalsOOH) towards a simpler analysis of carbohydrates (glucose, xylose, galactose and mannose). The final architecture of the back-propagation Artificial Neural Network (ANN) model had 36 input neurons and a hidden layer with 5 neurons. The ANN based prediction model has provided satisfactory concentrations for all carbohydrates; the obtained response had a maximum NRMSE of $12.4 \%$ with a maximum deviation of slopes in the obtained vs. expected comparison graph of $15 \%$. For all species, the comparison correlation coefficient was of $r \geq 0.99$ for the training subset and of $r \geq 0.96$ for the test subset.
\end{abstract}

(C) 2015 Elsevier B.V. All rights reserved.

\section{Introduction}

The biomass sugarcane bagasse is a by-product of the production process for sugar and ethanol from sugarcane. New applications for the bagasse have been developed and among them we can highlight the production of second generation biofuels (ethanol) $[1,2]$. Second generation ethanol is produced from the carbohydrates released from the cell walls of sugarcane bagasse and straw $[3,4]$.

Biomass as sugarcane bagasse is formed in its majority by lignocellulosic materials, in other words composed of hardly soluble carbohydrate polymers with crystalline and amorphous structures, formed by three main fractions: cellulose, hemicellulose and lignin $[3,4]$. The most abundant fraction is cellulose (32-44\%), a linear homopolysaccharide formed by glucose units strongly bound. Hemicellulose (27-32\%), consists of different carbohydrates, mainly xylose, configured in an easily hydrolysable chain. Finally, there is a series of aromatic alcohols polymerized, called

\footnotetext{
* Corresponding author. Tel.: +34 935813235; fax: +34 935812477.

E-mail addresses: manel.delvalle@uab.es, manel.delvalle@uab.cat (M. del Valle).
}

lignin fraction (19-24\%), that linked to hemicellulose wrap up the cellulose and protects it from the chemical or enzymatic hydrolytic attack $[3,4]$.

Hemicelluloses are a heterogeneous class of polymers configured in an easily hydrolysable chain formed by carbohydrates as, pentoses ( $\beta$-D-xylose, $\alpha$-L-arabinose), hexoses ( $\beta$-D-mannose, $\beta$-D-glucose, $\alpha$-D-galactose) and uronic acids ( $\alpha$-D-glucuronic, $\alpha$ D-4-O-methylgalacturonic and $\alpha$-D-galacturonic) $[5,6]$

Abundant applications of enzymatic sensors for carbohydrates are reported in literature, with the majority dedicated to glucose in contrast to non-enzymatic ones. In their description, there is a balance of advantages and disadvantages of which both are significant. Despite dominating the glucose sensor market, some enzymatic systems, as the oxidases, have one critical flaw such the oxygen dependency, and can be therefore questioned for maximum reliability; other, like the dehydrogenases are highly limited by the use of co-substrates, making more difficult their use. Apart, the biosensing features of enzymatic sugar biosensors can be highly impacted by the presence of other electroactive interferences that are always commonplace in real industrial samples; and still, they will always be constrained by usage of mild enzymatic conditions, being proteins that may suffer denaturalization $[7,8]$. 
Sensitive and selective carbohydrate sensors are relevant for use in blood sugar monitoring, food industry, bio-processing and in the development of renewable and sustainable fuel cells. Nonenzymatic carbohydrate electrodes used in direct oxidation may show considerably greater sensitivity, with high oxidation currents being reported over the past decade [8].

The development of non-enzymatic carbohydrates sensors has risen at a considerable rate, many efforts have been made to find new electrocatalytic materials for oxidation of glucose and carbohydrates such as: cobalt hydroxide nanoparticles electrodeposited on the surface of glassy carbon electrode [9], multi-wall carbon nanotubes containing copper oxide nanoparticles [10], copper hydroxide nanotubes [11], nickel hydroxide nanoparticles on boron-doped diamond electrodes [12], carbon nanotubes/copper composite electrodes [13], copper(II) oxide nanorod bundles [14], gold nanoparticle-constituted nanotube array electrode [15], palladium nanoparticles supported on functional carbon nanotubes[16], palladium nanoparticles distributed on surfactant-functionalized multi-wall carbon nanotubes [17], Nickel/cobalt alloys modified electrodes [18], nickel hydroxide deposited indium tin oxide electrodes [19], Au-CuO nanoparticles decorated reduced graphene oxide [20] and glassy carbon electrode decorated with multi-wall carbon nanotubes with nickel oxy-hydroxide [21].

Accurate measurement of the carbohydrate content in the samples of sugarcane bagasse is very important, because the quantification of these sugars is directly linked to what type of microorganism has to be used in fermentation and is also extremely important in the evaluation and optimization of different processes for the production of second generation ethanol [2].

The use of non-enzymatic chemically modified electrodes represents an attractive alternative to classical analytical methods for detection of carbohydrates; unfortunately, these sensors exhibit lower selectivity than those enzymatic ones, discriminating with difficulties individual carbohydrates. Although this can be as the possibility to predict total carbohydrates present, the only alternative to the lack of selectivity seen can be the use of chromatographic stages [22-25]. Besides that to such specific equipment are high cost, laboratory conditions and trained personnel.

A new methodology in the sensors field is the use of sensors in arrays coupled with complex data treatment, that is, the use of electronic tongues; these are versatile sensor systems capable to simultaneously monitor the level of different analytes, or analytes in presence of their interferents, or to resolve mixtures of similar analytes [26-31].

An electronic tongue is a multisensor system, which consists of a number of low-selective sensors and uses advanced mathematical procedures for signal processing based on Pattern Recognition and/or Multivariate data analysis - Artificial Neural Networks (ANNs), Principal Component Analysis (PCA), etc. [32]. Therefore, the electronic tongue is an analytical system applied to liquid analysis formed by a sensor array in order to generate multidimensional information, plus a chemometric processing tool to extract meaning from these complex data [27,33].

From the beginning of this technique, there are electronic tongues devised using potentiometric sensors, but also using of the voltammetric type. In these original works, originated at the laboratories of Prof. Winquist in Linkoping (Sweden), the sensor array was formed by an array of different metallic disc electrodes, and a scanning voltammetric technique was used to generate the analytical information [30]. The voltammetric principle has also been applied to develop electronic tongues since its early years, such as simultaneous identification and quantification of nitrocontaining explosives by advanced chemometric data treatment of cyclic voltammetry at screen-printed electrodes [28], instrumental measurement of wine sensory descriptors using a voltammetric electronic tongue [33], evaluation of red wines polyphenolic content by means of a voltammetric e-tongue with an optimized sensor array [34], voltammetric electronic tongue for the qualitative analysis of beers [27] and cava wine authentication employing a voltammetric electronic tongue [35].

The present work reports the characterization and application of a voltammetric electronic tongue using glassy carbon electrode modified with multi-wall carbon nanotubes decorated with metal (Copper, Cobalt, Paladium, Gold and Nickel) oxy-hydroxide nanoparticles (GCE/MWCNT/MetalsOOH) towards the analysis of carbohydrates (galactose, glucose, xylose and mannose). As such, it combines the responses from voltammetric electronic tongue formed by GCE/MWCNT/MetalsOOH modified electrodes, plus an advanced response model employing a specifically trained Artificial Neural Network (ANNs), with pretreatment of the data employing standard compression methods (Wavelet transform) and pruning step. This preprocessing is needed given the high dimensionality of the considered data.

\section{Materials and methods}

\subsection{Reagent and instruments}

Purified multiwalled carbon nanotubes (MWCNTs) with an outer diameter of $30 \mathrm{~nm}$ were purchased from SES Research (Houston, Texas, USA). Cobalt (II) chloride hexahydrate $\left(\mathrm{CoCl}_{2} \cdot 6 \mathrm{H}_{2} \mathrm{O}\right)$, nickel(II) sulfate hexahydrate $\left(\mathrm{NiSO}_{4} \cdot 6 \mathrm{H}_{2} \mathrm{O}\right)$, palladium chloride $\left(\mathrm{PdCl}_{2}\right)$, ammonium fluoride $\left(\mathrm{NH}_{4} \mathrm{~F}\right)$, boric acid $\left(\mathrm{H}_{3} \mathrm{BO}_{3}\right)$, sodium borohydride $\left(\mathrm{NaBH}_{4}\right), \mathrm{N}-\mathrm{N}$-Dimethylformamide $99.8 \%\left(\mathrm{C}_{3} \mathrm{H}_{7} \mathrm{NO}\right)$, D-Glucose, D-Galactose, D-Mannose, D-Xylose $\mathrm{HAuCl}_{4} \cdot 3 \mathrm{H}_{2} \mathrm{O}$, Trisodium Citrate, Sodium dodecyl sulfate (SDS) and sodium hydroxide $(\mathrm{NaOH})$ were purchased from Sigma-Aldrich (St. Louis, MO, USA). Sulphuric acid $96 \%\left(\mathrm{H}_{2} \mathrm{SO}_{4}\right)$, nitric acid $69 \%\left(\mathrm{HNO}_{3}\right)$ $\mathrm{CuSO}_{4} .5 \mathrm{H}_{2} \mathrm{O}$ and ammonia $32 \%\left(\mathrm{NH}_{3}\right)$ were purchased from Merck (Darmstad, Germany). All solutions were made using MilliQ water from MilliQ System (Millipore, Billerica, MA, USA). The buffer used for formation of nickel and cobalt nanoparticles was phosphate buffer $\left(0.1 \mathrm{~mol} \mathrm{~L}^{-1} \quad \mathrm{Na}_{2} \mathrm{HPO}_{4}\right.$ and $0.1 \mathrm{~mol} \mathrm{~L}^{-1}$ mono-hydrated $\mathrm{NaH}_{2} \mathrm{PO}_{4} \mathrm{pH}$ 7.0).

\subsection{Characterization by scanning electron microscopy}

Transmission electron microscopy (TEM) images and microanalysis patterns were recorded with a JEOL JEM-2011 microscope equipped with an energy dispersive spectroscopy (EDS) detector. Scanning electron microscopy (SEM) images were performed on JSM 7500F model Brand Jeol FE-SEM microscope.

\subsection{Measuring procedure}

The amperometric measurement cell was formed by the 5 (five) GCE/MWCNT/MetalsOOH modified electrodes plus a reference double junction $\mathrm{Ag} / \mathrm{AgCl}$ electrode (Thermo Orion 900200, Beverly, MA, USA) and a commercial platinum counter electrode (Model 52-67, Crison Instruments, Barcelona, Spain). Cyclic voltammetry measurements were taken using a 6-channel AUTOLAB PGSTAT20 potentiostat (Ecochemie, Netherlands), in multichannel configuration, using the GPES Multichannel 4.7 software package. For this, potentials were cycled between $-0.7 \mathrm{~V}$ and $+0.8 \mathrm{~V}$ vs. $\mathrm{Ag} / \mathrm{AgCl}$, with a scan rate of $50 \mathrm{mV} \mathrm{s}^{-1}$. Electroanalytical experiments were carried out at room temperature $\left(25^{\circ} \mathrm{C}\right)$ under quiescent conditions. Briefly, samples were measured as described with the GCE/MWCNT/MetalsOOH sensor voltammetric array, and afterwards obtained responses were analysed by means of the different chemometric tools described below. 


\subsection{Experimental design for the quantification model}

In order to prove the capabilities of the ET to achieve the simultaneous quantification of different carbohydrates mixtures, resolution of Galactose, Glucose, Xylose and Mannose a response model using ANNs was prepared. To this aim, a total set of 46 samples were manually prepared with a concentration range of 0.5 to $2.5 \mathrm{mM}$ for each carbohydrate. The set of samples was divided into two data subsets: a training subset formed by 36 samples (78\%) which were distributed based on a L36 Taguchi design [36], with 4 factors and 3 levels, and used to build the response model, plus 10 additional samples (22\%) for the testing subset, distributed randomly along the experimental domain and used to evaluate the model predictive ability.

\subsection{Data processing}

In order to reduce the large dataset generated for each sample ( 5 sensors x 336 current values at different potential) a preprocessing stage was necessary to compress the original data. The objective of this step was to reduce the complexity of the input data while preserving the relevant information, the compression of the data allows also to reduce the training time, to avoid redundancy in input data and to obtain a model with better generalization ability.

The data was compressed using the Discrete Wavelet Transform (DWT) [37]: each voltammogram was compressed using Daubechies 4 wavelet mother function and a fourth decomposition level. In this manner, the original data was reduced to 135 coefficients without any loss of relevant information; additionally Causal Index pruning strategy [38] was employed to further refine the model by eliminating the inputs that make relatively small contributions to the model. With this, the 135 inputs per sample were further reduced down to 36 coefficients, achieving a total compression ratio up to $97.9 \%$.

\subsection{Preparation of electrodes for electronic tongue}

\subsubsection{Decoration of MWCNTs with $\mathrm{Pd}, \mathrm{CuO}$ and Au nanoparticles}

Before the modification with metal nanoparticles MWCNTs were purified with an acidic pre-treatment. Briefly, the MWCNTs were dispersed in a 3:1 mixture of concentrated $\mathrm{H}_{2} \mathrm{SO}_{4} / \mathrm{HNO}_{3}$ acids using an ultrasonic bath for 90 min [39]. Purified MWCNTs were then used for further modification with different metal nanoparticles.

\subsubsection{Palladium decorated multi-wall carbon nanotubes (MWCNT/Pd)}

This modification was performed following the protocol reported by Cipri et al. [39]. Briefly, a flask was prepared with a solution consisting of $\mathrm{PdCl}_{2}\left(14.0 \times 10^{-3} \mathrm{~mol} \mathrm{~L}^{-1}\right), \mathrm{H}_{3} \mathrm{BO}_{3}$ $\left(1.57 \times 10^{-1} \mathrm{~mol} \mathrm{~L}^{-1}\right)$ and $\mathrm{NH}_{4} \mathrm{~F}\left(6.67 \times 10^{-2} \mathrm{~mol} \mathrm{~L}^{-1}\right)$. Then, purified MWCNTs $(100 \mathrm{mg}$ ) were dispersed in the above solution via ultrasonication for approximately $1 \mathrm{~h}$ and the $\mathrm{pH}$ was adjusted to 8-9. A solution of $\mathrm{NaBH}_{4}(17 \mathrm{~mL})$ was added dropwise under vigorous stirring and followed by another $8 \mathrm{~h}$ of stirring to complete the reaction. The MWCNT/Pd were filtered, washed and then dried under vacuum at $50^{\circ} \mathrm{C}$.

\subsubsection{Gold decorated multiwalled carbon nanotubes (MWCNT/Au)}

The decoration with Gold was performed following and slightly modifying the procedure reported by Shi et al. [40]. Briefly, a flask was prepared with a solution of $0.5 \mathrm{~mL}$ of $\mathrm{HAuCl}_{4} \cdot 3 \mathrm{H}_{2} \mathrm{O}$ $\left(1.0 \times 10^{-2} \mathrm{~mol} \mathrm{~L}^{-1}\right), 0.5 \mathrm{~mL}$ of an aqueous solution of trisodium citrate $\left(1.0 \times 10^{-2} \mathrm{~mol} \mathrm{~L}^{-1}\right)$ and $18.4 \mathrm{~mL}$ of double distilled water. Purified CNTs (20 mg for a Au loading ratio of $10 \% \mathrm{wt} \%$ ) were added to the above solution and then $10-12 \mathrm{~mL}$ of ethanol were immediately introduced under vigorous stirring and the mixture was ultrasonicated for $10 \mathrm{~min}$. Ice-cold freshly prepared $\mathrm{NaBH}_{4}$ aqueous solution $\left(0.6 \mathrm{~mL}, 0.1 \mathrm{~mol} \mathrm{~L}^{-1}\right)$ was then added to the above mixture while stirring and leaving it overnight. The MWCNT/Au were separated by centrifuging, washed with double distilled water for several cycles and then dried under vacuum overnight at $50^{\circ} \mathrm{C}$.

\subsubsection{Carbon nanotubes integrated with copper oxide nanoleaves (MWCNT/CuO)}

The modification with copper was performed by modifying the procedure reported by Yang et al. [41]. Briefly, in a flask sodium dodecyl sulfate (SDS) was dissolved $\left(0.1 \mathrm{~mol} \mathrm{~L}^{-1}\right)$ in $300.0 \mathrm{~mL}$ of distilled water stirring at $60^{\circ} \mathrm{C}$; Then $50 \mathrm{mg}$ of purified MWCNTs were ultrasonically dispersed in $25.0 \mathrm{~mL}$ of DMF and then added to the SDS solution and ultrasonicated for $10 \mathrm{~min}$, then $\mathrm{CuSO}_{4} \cdot 5 \mathrm{H}_{2} \mathrm{O}(2.5 \mathrm{~g})$ was added to the above solution and ultrasonicated for $10 \mathrm{~min}$. The solution of $100 \mathrm{~mL}$ of $\mathrm{NaOH}\left(0.5 \mathrm{~mol} \mathrm{~L}^{-1}\right)$ was slowly dropped into the above solution and then stirred for $10.0 \mathrm{~min}$. The resulting solution was then centrifuged, washed with doubly distilled water for few cycles and then dried at $60^{\circ} \mathrm{C}$.

\subsubsection{Glassy carbon surface modification GCE/MWCNT/PdOOH}

All surfaces of the GC electrodes were polished with $0.3 \mu \mathrm{m}$ alumina powder (Merck) and cleaned in ethanol and Milli-Q water.

$2.0 \mathrm{mg}$ MWCNT/Pd were dispersed in $1.0 \mathrm{~mL} \mathrm{N,N-}$ dimethylformamide (DMF) with a ultrasonic bath to give a $2.0 \mathrm{mg} \mathrm{mL}^{-1}$ black solution. 3 steps of $10 \mu \mathrm{L}$ of the black solution were dropped on the GC electrode surface to prepare the GCE/MWCNT/Pd electrode surface at the end of each step, the electrode was allowed to dry at $50^{\circ} \mathrm{C}$ for $3.0 \mathrm{~h}$. After modification, the glassy carbon electrode modified with carbon nanotubes containing palladium nanoparticles (GCE/MWCNT/Pd) was passivated to form palladium oxy-hydroxide using a solution of $\mathrm{NaOH} 0.1 \mathrm{~mol} \mathrm{~L}^{-1}$ in the potential range of -0.8 to $0.8 \mathrm{~V}$ at a scan rate of $50 \mathrm{mV} \mathrm{s}^{-1}$ for 20 cycles in cyclic voltammetry. Then, the GCE/MWCNT/PdOOH was washed thoroughly with deionized water and dried. The electrochemical behavior of the GCE/MWCNT/PdOOH electrode was evaluated in aqueous solutions with supporting electrolyte $\mathrm{NaOH} 0.1 \mathrm{~mol} \mathrm{~L}^{-1}$.

\subsubsection{GCE/MWCNT/AuO}

$2.0 \mathrm{mg}$ MWCNT/Au were dispersed in $1.0 \mathrm{~mL} \quad \mathrm{~N}, \mathrm{~N}-$ dimethylformamide (DMF) with a ultrasonic bath to give a $2.0 \mathrm{mg} \mathrm{mL}^{-1}$ black solution. 3 steps of $10 \mu \mathrm{L}$ of the black solution were dropped on the GC electrode surface to prepare the GCE/MWCNT/Au electrode surface. At the end of each step the electrode was allowed to dry at $50^{\circ} \mathrm{C}$ for $3.0 \mathrm{~h}$. After each modification the glassy carbon electrode modified with carbon nanotubes containing gold nanoparticles (GCE/MWCNT/Au) was passivated to form gold oxide using a solution of $\mathrm{NaOH} 0.1 \mathrm{~mol} \mathrm{~L}^{-1}$ in the potential range of -0.4 to $0.5 \mathrm{~V}$ at a scan rate of $50 \mathrm{mV} \mathrm{s}^{-1}$ for 20 cycles in cyclic voltammetry. Then, the GCE/MWCNT/AuO was washed thoroughly with deionized water and dried. The electrochemical behavior of the GCE/MWCNT/AuO electrode was evaluated in aqueous solutions with supporting electrolyte $\mathrm{NaOH}$ $0.1 \mathrm{~mol} \mathrm{~L}^{-1}$.

\subsubsection{GCE/MWCNT/CuOOH}

$2.0 \mathrm{mg} \mathrm{MWCNT} / \mathrm{Cu}$ was dispersed in $20.0 \mathrm{~mL} \mathrm{~N}, \mathrm{~N}-$ dimethylformamide (DMF) with a ultrasonic bath to give a $0.1 \mathrm{mg} \mathrm{mL}^{-1}$ black solution. 2 steps of $10 \mu \mathrm{L}$ of the black solution were dropped at the GC electrode surface to prepare the 

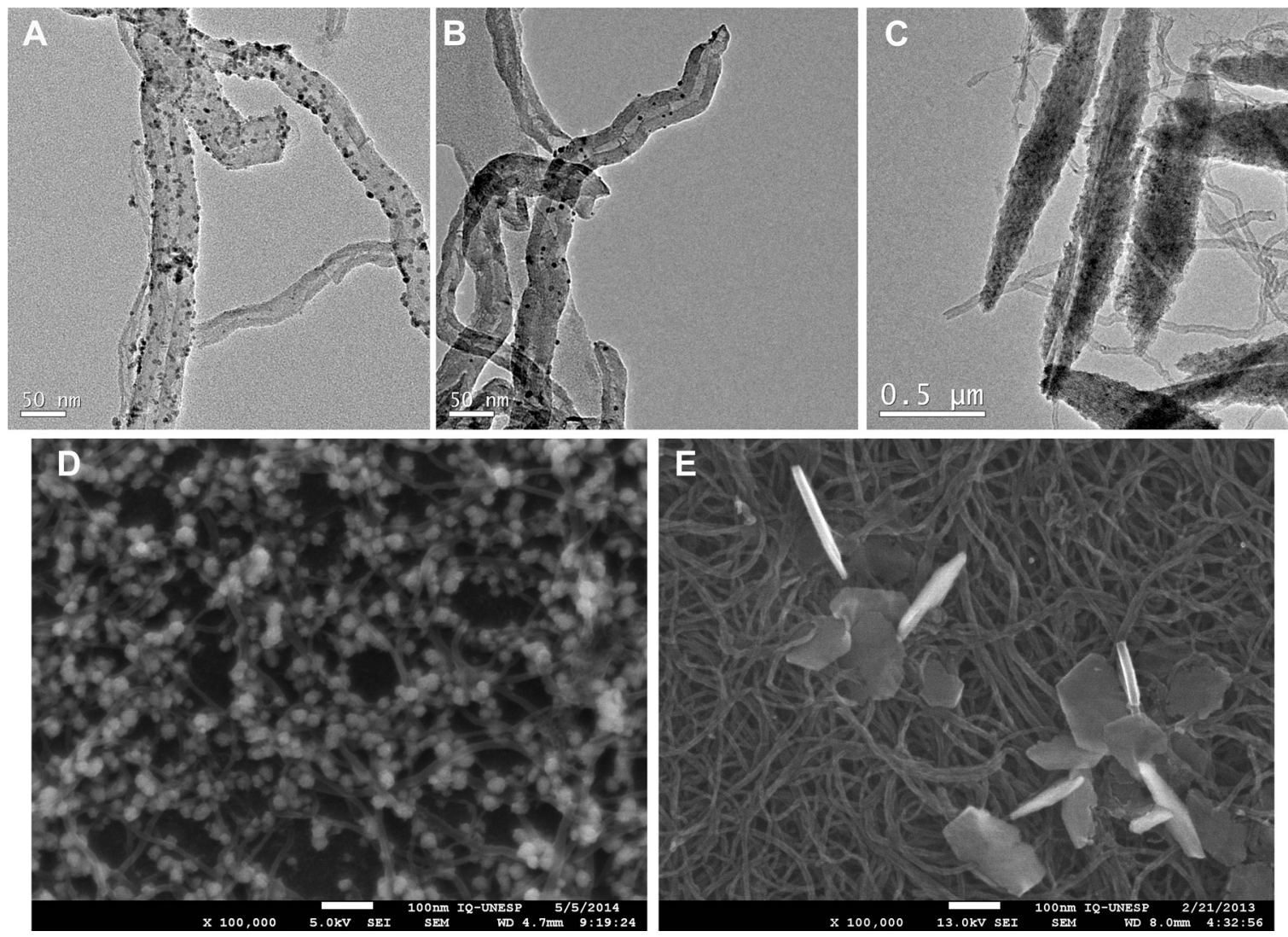

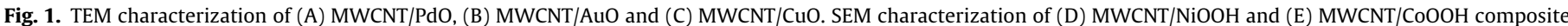
materials.

GCE/MWCNT/Cu electrode surface at the end of each step, the electrode was dried at $50^{\circ} \mathrm{C}$ for $3.0 \mathrm{~h}$. After each modification the glassy carbon electrode modified with carbon nanotubes containing copper nanoparticles (GCE/MWCNT/Cu) was passivated to form copper oxy-hydroxide with a solution of $\mathrm{NaOH} 0.1 \mathrm{~mol} \mathrm{~L}^{-1}$ in the potential range of -0.5 to $0.3 \mathrm{~V}$ at a scan rate of $50 \mathrm{mV} \mathrm{s}^{-1}$ for 20 cycles in cyclic voltammetry. Then, the GCE/MWCNT/CuOOH was washed thoroughly with deionized water and dried. The electrochemical behavior of the GCE/MWCNT/CuOOH electrode was evaluated in aqueous solutions with supporting electrolyte $\mathrm{NaOH} 0.1 \mathrm{~mol} \mathrm{~L}^{-1}$

\subsubsection{GCE/MWCNT/COOOH}

$1.0 \mathrm{mg}$ MWCNT was dispersed in $10.0 \mathrm{~mL}$ N,N-dimethylformamide (DMF) with a ultrasonic bath to give a $0.1 \mathrm{mg} \mathrm{mL}^{-1}$ black solution. $5.0 \mu \mathrm{L}$ of the black solution was deposited at the GC electrode surface to prepare the GCE/MWCNT electrode surface. Immediately after the glassy carbon electrode was modified with carbon nanotubes (GCE/MWCNT) cobalt nanoparticles were electrodeposited using $1.0 \times 10^{-3} \mathrm{~mol} \mathrm{~L}^{-1}$ of $\mathrm{CoCl}_{2}$ in phosphate buffer $0.1 \mathrm{~mol} \mathrm{~L}^{-1}$ ( $\mathrm{pH} \mathrm{6.5)}$. The electrodeposition was carried out by cyclic voltammetry in a potential range of -1.1 to $1.2 \mathrm{~V}$ at a rate of $100 \mathrm{mV} \mathrm{s}^{-1}$ for 30 cycles [42]. To complete the modification, the glassy carbon electrode modified with carbon nanotubes containing cobalt nanoparticles (GCE/MWCNT/Co) was passivated to form cobalt oxy-hydroxide at $\mathrm{NaOH} 0.1 \mathrm{~mol} \mathrm{~L}^{-1}$ in the potential range of -0.3 to $0.7 \mathrm{~V}$ at a scan rate of $50 \mathrm{mV} \mathrm{s}^{-1}$ for 45 cycles in cyclic voltammetry. Then, the GCE/MWCNT/CoOOH was washed thoroughly with deionized water and dried. The electrochemical behavior of the GC/MWCNT/CoOOH electrode was evaluated in aqueous solutions with supporting electrolyte $\mathrm{NaOH} 0.1 \mathrm{~mol} \mathrm{~L}^{-1}$.

\subsubsection{GCE/MWCNT/NiOOH}

$1.0 \mathrm{mg}$ MWCNT was dispersed in $10.0 \mathrm{~mL} \mathrm{~N}, \mathrm{~N}-$ dimethylformamide (DMF) with a ultrasonic bath to give a $0.1 \mathrm{mg} \mathrm{mL}{ }^{-1}$ black solution. $5.0 \mu \mathrm{L}$ of the black solution was deposited at the GC electrode surface to prepare the GC/MWCNT electrode surface. Immediately after the glassy carbon electrode was modified with carbon nanotubes (GCE/MWCNT) a solution of $\mathrm{NiSO}_{4}\left(5.0 \times 10^{-3} \mathrm{~mol} \mathrm{~L}^{-1}\right)$, in phosphate buffer $0.1 \mathrm{~mol} \mathrm{~L}^{-1}(\mathrm{pH}$ 6.5), was used for the electrodeposition of nickel nanoparticles. The electrodeposition was carried out by cronoamperometry at a potential of $-1.3 \mathrm{~V}$ for $30 \mathrm{~s}$. To complete the modification, the glassy carbon electrode modified with carbon nanotubes containing nickel nanoparticles (GCE/MWCNT/Ni) was passivated to form nickel oxy-hydroxide at $\mathrm{NaOH} 0.5 \mathrm{~mol} \mathrm{~L}^{-1}$ in the potential range of -0.5 to $1.0 \mathrm{~V}$ at a scan rate of $100 \mathrm{mV} \mathrm{s}^{-1}$ for 30 cycles in cyclic voltammetry [43]. Then, the GCE/MWCNT/NiOOH was washed thoroughly with deionized water and dried. The electrochemical behavior of the GCE/MWCNT/NiOOH electrode was evaluated in aqueous solutions with supporting electrolyte $\mathrm{NaOH} 0.1 \mathrm{~mol} \mathrm{~L}^{-1}$.

\section{Results and discussion}

\subsection{Characterization of GCE/MWCNT/Metals oxy-hydroxide modified electrodes}

TEM characterization of the MWCNT/Pd is displayed in Fig. 1A as can be observed the size of the nanoparticles is below $10 \mathrm{~nm}$. The quasi-homogeneous distribution may be due to the small longitudinal size in comparison to the diameter of the nanotubes and to the in-situ growth of the palladium nanoparticles. This hybrid nanomaterial is expected to give better catalytic properties than the two materials by themselves. The morphology of 

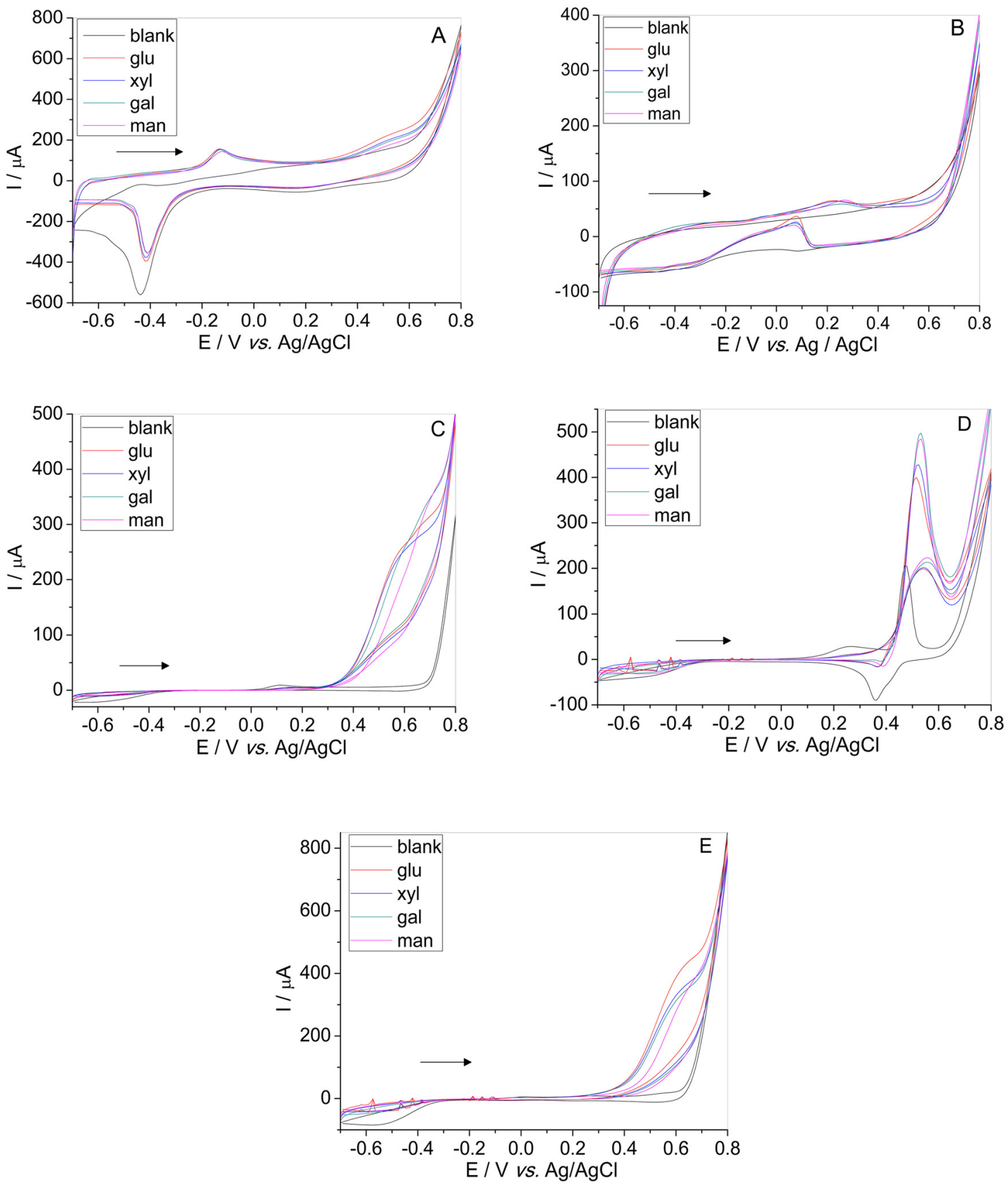

Fig. 2. Example of the different voltammograms obtained with (A) GCE/MWCNT/PdOOH, (B) GCE/MWCNT/AuO, (C) GCE/MWCNT/CuOOH, (D) GCE/MWCNT/NiOOH and (E) GCE/MWCNT/CoOOH for $0.1 \mathrm{~mol} \mathrm{~L}^{-1} \mathrm{NaOH}$ and stock solutions $5.0 \times 10^{-3} \mathrm{~mol} \mathrm{~L}^{-1}$ of each of the five carbohydrates (blank) Absence, (glu) Glucose,(xyl) Xylose, (gal) Galactose and (man) Mannose.

the MWCNT/Au composites was further characterized with TEM (Fig. 1B) and confirmed that the Au-NPs were attached on the MWCNT and ends, showing a diameter of about 4-7 nm. The TEM Fig. 1C shows that each leaf-like CuO polycrystalline is composed of several single-crystalline pieces, which suggest the coexistence of $\mathrm{CuO}$ and MWCNTs. Therefore, MWCNTs and $\mathrm{CuO}$ nanoleaves do indeed form a nanocomposite, and are not simply mixed together. In Fig. 1D it can be observed regular and spherical particles with size about $32 \mathrm{~nm}$ and their homogeneous distribution over the MWCNT. This better distribution and uniform sizes may be responsible for lower limits of detection in the analysis of sugars by the electrode modified with MWCNT/Ni [44,45]. In Fig. 1E it can be observed that the particles are in a wire shape. Some of the particles are in vertical position taking a representative wire; the average particle size is around $20 \mathrm{~nm}$ for particles in an upright position as in the case of wire and $185 \mathrm{~nm}$ for the particles in horizontal position.

\subsection{GCE/MWCNT/Metals oxy-hydroxide modified electrodes response}

The voltammetric responses for each of the electrodes towards individual compounds was the first response feature checked. That is, to ensure that enough differentiated signals were observed for the different electrodes, generating rich data that might be a useful departure point for the multivariate calibration model. 
Table 1

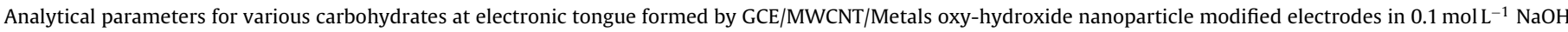
by Cyclic Voltammetry $\left(v=50 \mathrm{mV} \mathrm{s}^{-1} ; n=3\right)$.

\begin{tabular}{|c|c|c|c|c|}
\hline \multicolumn{5}{|l|}{ Palladium } \\
\hline Carbohydrate & Limit of Detection (mM) & Limit of Quantification (mM) & Sensitivity $\left(\mu \mathrm{A} \mathrm{mM}^{-1}\right)$ & Concentration range $(\mathrm{mM})$ \\
\hline Glucose & 0.32 & 1.05 & 25.5 & $0.4-5.0$ \\
\hline Xylose & 0.38 & 1.25 & 11.9 & $0.4-5.0$ \\
\hline Galactose & 0.87 & 2.97 & 14.1 & $0.9-5.0$ \\
\hline Mannose & 0.08 & 0.27 & 14.3 & $0.2-5.0$ \\
\hline \multicolumn{5}{|l|}{ Gold } \\
\hline Glucose & 0.64 & 2.11 & 7.3 & $0.8-5.0$ \\
\hline Xylose & 0.62 & 2.04 & 5.8 & $0.8-5.0$ \\
\hline Galactose & 0.57 & 1.88 & 5.5 & $0.6-5.0$ \\
\hline Mannose & 1.00 & 3.33 & 6.0 & $1.0-5.0$ \\
\hline \multicolumn{5}{|l|}{ Copper } \\
\hline Glucose & 0.10 & 0.33 & 51.1 & $0.2-5.0$ \\
\hline Xylose & 0.06 & 0.19 & 49.5 & $0.2-5.0$ \\
\hline Galactose & 0.38 & 1.26 & 41.5 & $0.4-5.0$ \\
\hline Mannose & 0.36 & 1.19 & 7.18 & $0.4-5.0$ \\
\hline \multicolumn{5}{|l|}{ Nickel } \\
\hline Glucose & 0.23 & 0.76 & 32.0 & $0.4-5.0$ \\
\hline Xylose & 0.38 & 1.26 & 39.2 & $0.4-5.0$ \\
\hline Galactose & 0.41 & 1.36 & 46.7 & $0.5-5.0$ \\
\hline Mannose & 0.47 & 1.56 & 42.0 & $0.5-5.0$ \\
\hline \multicolumn{5}{|l|}{ Cobalt } \\
\hline Glucose & 0.31 & 1.03 & 83.6 & $0.4-5.0$ \\
\hline Xylose & 0.10 & 0.33 & 67.9 & $0.2-5.0$ \\
\hline Galactose & 0.25 & 0.83 & 75.7 & $0.4-5.0$ \\
\hline Mannose & 0.38 & 1.26 & 69.2 & $0.4-5.0$ \\
\hline
\end{tabular}

To this aim, and under the described conditions in Section 2.5, individual standard solutions of galactose, glucose, xylose and mannose were analyzed and their voltammograms inspected, in Fig. 2 displays the voltammetric behavior from the different GCE/MWCNT/MetalsOOH modified electrodes in the electrooxidation study of carbohydrates.

In Fig. 2 (A) the selected is shown the voltammogram of GCE/MWCNT/PdOOH electrode during electro-oxidation of carbohydrates that occurs at potentials around $-0.1 \mathrm{~V}$ vs. $\mathrm{Ag} / \mathrm{AgCl}$ associated with an anodic peak current and also the decrease in cathodic peak current, the results suggest that $\mathrm{Pd}^{(\mathrm{II})} / \mathrm{Pd}^{(\mathrm{I})}$ redox couple in form of $\mathrm{PdOOH}$ [46] can catalyze the electro-oxidation of carbohydrates.

In Fig. 2 (B) is shown the voltammogram of GCE/MWCNT/AuO electrode during electro-oxidation of carbohydrates that occurs at potential around $0.25 \mathrm{~V}$ vs. $\mathrm{Ag} / \mathrm{AgCl}$, with the appearance of the anodic peak current and cathodic peak current of reoxidation at potentials $-0.07 \mathrm{~V} \mathrm{vs}$. $\mathrm{Ag} / \mathrm{AgCl}$. This can be state as typical behavior of gold electrodes, which electrocatalytic activity of can be rationalized by the incipient hydrous oxide/adatom model can catalyze the oxidation of carbohydrates $[15,47,48]$.

The voltammogram of $\mathrm{GCE} / \mathrm{MWCNT} / \mathrm{CuOOH}$ is shown in Fig. 2(C), for which in electro-oxidation of carbohydrates occurs at a potential of around $0.60 \mathrm{~V} \mathrm{vs}$. $\mathrm{Ag} / \mathrm{AgCl}$, with the appearance of the anodic wave. During the positive scan, the $\mathrm{Cu}$ nanoparticles can be oxidized to $\mathrm{CuOOH}$. The $\mathrm{Cu}^{(\mathrm{III})} / \mathrm{Cu}^{(\mathrm{II})}$ redox couple can catalyze the oxidation of carbohydrates [11,49,50].

The electro-oxidation of carbohydrates on GC/MWCNT/NiOOH electrode, as shown in the Fig. 2 (D), occurred at a potential of around $0.52 \mathrm{~V}$ vs. $\mathrm{Ag} / \mathrm{AgCl}$ associated with increased anodic peak current and decrease in cathodic peak current. The results suggest that $\mathrm{Ni}^{(\mathrm{III})} / \mathrm{Ni}^{(\mathrm{II})}$ redox couple can catalyze the electro-oxidation of carbohydrates [21].
The voltammogram of GCE/MWCNT/CoOOH shown in Fig. 2(E) demonstrated electro-oxidation of carbohydrates occurring at potential around $0.65 \mathrm{~V}$ vs. $\mathrm{Ag} / \mathrm{AgCl}$, with the appearance of the anodic wave. This fact suggests that carbohydrates are oxidized by $\mathrm{CoOOH}$ species through $\mathrm{Co}^{(\mathrm{IV})} / \mathrm{Co}^{(\mathrm{III})}$ redox couple moiety and through a cyclic mediation redox process $[9,51]$.

The observed results as a whole, indicate the different GCE/MWCNT/MetalsOOH modified electrodes forming the electronic tongue can catalyze the electro-oxidation of carbohydrates (galactose, Glucose, Xylose and Mannose) to ketones, forming galactonolactone, gluconolactone, xylonolactone and mannonalactone, respectively [21]. Besides, clearly differentiated curves are obtained for each modified electrode and each considered sugar giving the desirable condition for an Electronic Tongue (ET) study.

This cross-response nature of the voltammograms can be summarized when plotting max currents (sensitivities) and oxidation peak potential observed for the 5 MWCNT/Metals NPs modified electrodes. This representation is shown in Fig. S3, where it can be observed that carbohydrates anodic peak current (Ipa) is different according to each metal nano-composite of the ET formed by GCE/MWCNT/Metals oxy-hydroxides modified electrodes and was also observed that the oxidation potentials (Epa) showed different behaviors according to each metal, this is a desirable condition for any ET study.

The Principal Component Analysis (PCA) is one of the most important methods used in chemometrics and it is the basis for many standards recognition, is a way of reducing a large multivariate data matrix into a matrix with a much smaller number of variables, without losing important information within the data. The principle behind PCA is that the multivariate data can be decomposed by linear projections onto a new co-ordinate system. The new axes, known as principal components (PCs), are orientated so that the first PC captures the largest amount of common variance 


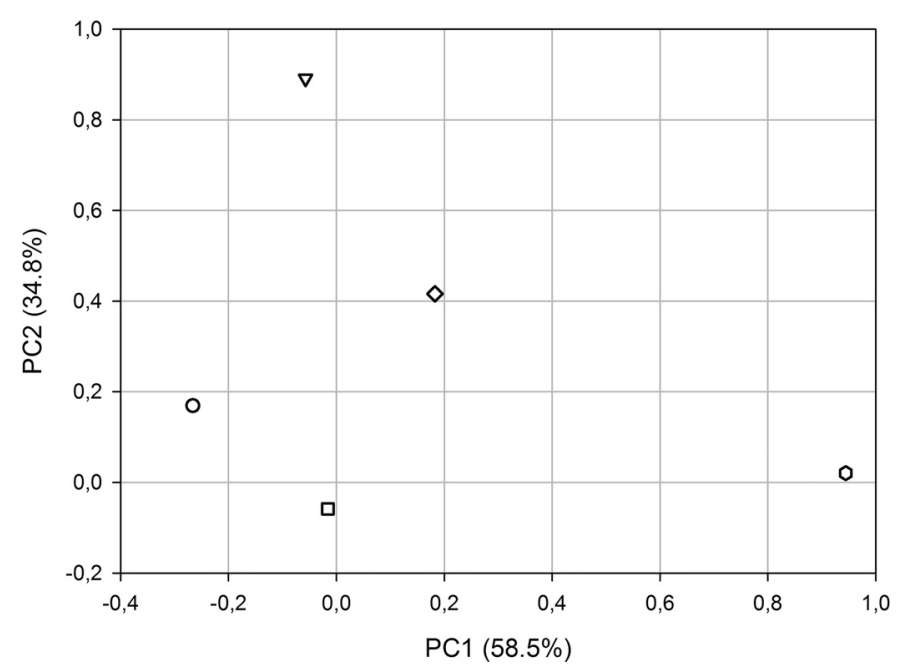

Fig. 3. PCA analysis loadings plot for five GCE/MWCNT/Metals oxy-hydroxide nanoparticle modified electrodes (metals $=(\square)$ gold, $(\nabla)$ palladium, $(0)$ copper, $(\diamond)$ nickel and $(\bigcirc)$ cobalt).

[52]. PCA can be one way to demonstrate the complementary of the generated information by each electrode, if electrodes are redundant they would appear superimposed, while different response will manifest in their separation. In Fig. 3 is shown the PCA for the five GCE/MWCNT/MetalsOOH modified electrodes (metals = gold, palladium, copper, nickel and cobalt); the PCA was prepared by treatment of the sensitivities of carbohydrates and was observed that each sensor showed performance in different regions this is
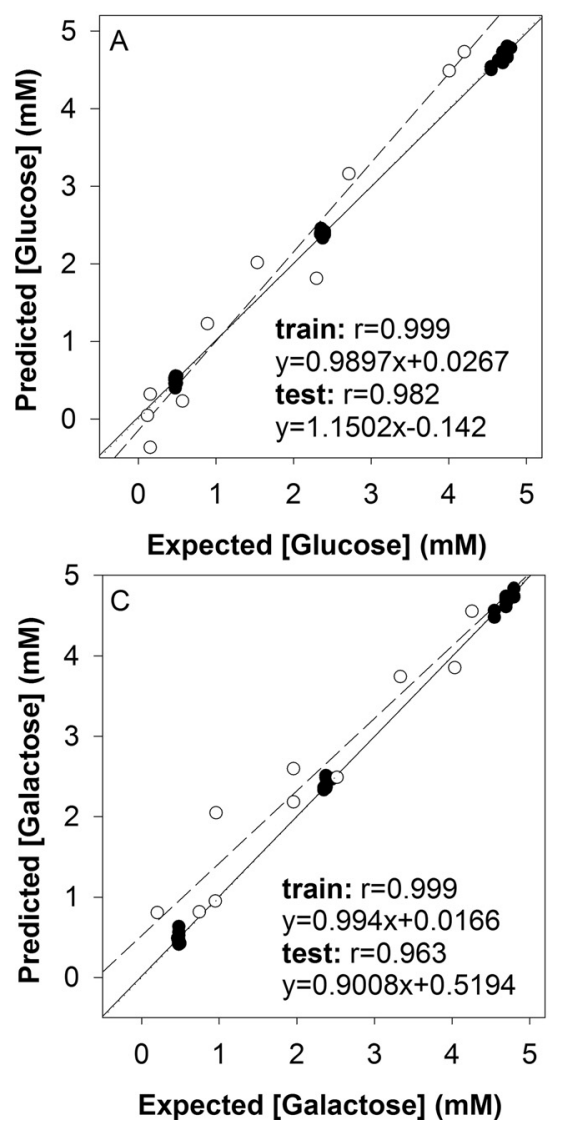

very positive because that is a desirable condition for any ET study, justifying the inclusion of the five prepared electrodes in the sensor array.

The analytical reproducibility (\%RSD) for the sensors was estimated using standard solutions of $2 \times 10^{-3} \mathrm{~mol} \mathrm{~L}^{-1}$ glucose measured along 3 different days, obtaining values for GCE/MWCNT/AuO of $3.28 \%$, for GCE/MWCNT/PdO $6.89 \%$, for GCE/MWCNT/CuOOH 3.85\%, for GCE/MWCNT/NiOOH $1.73 \%$ and for GCE/MWCNT/CoOOH 6.35\%. The analytical reproducibilities shown seem reasonable values, because the electrodes are subjected to analysis of many samples thus requiring maintain its reproducibility and stability.

Complete calibrations of considered sugars were conducted in $0.1 \mathrm{~mol} \mathrm{~L}^{-1} \mathrm{NaOH}$ solution with scan rate of $50 \mathrm{mV} \mathrm{s}^{-1}$ in order to fully characterize the used sensors. It was observed in all cases an increase of anodic peak current which was linear with the increase of concentration of sugars; Table 1 shows the electrochemical parameters for all carbohydrates studied. We observed that the electronic tongue formed by GCE/MWCNT/MetalsOOH modified electrodes has good amperometric sensitivity. The values of limit of detection and quantification are very close, meaning that the behavior of the different sugars on the electrode is comparable. Therefore we may apply the electronic tongue in the same concentration range for all sugars considered.

\subsection{Building of the ANN Model}

For the electronic tongue study, a total set of 46 carbohydrate standard mixtures were manually prepared (shown in Fig. S2 supplementary material), 36 corresponding to the train subset and
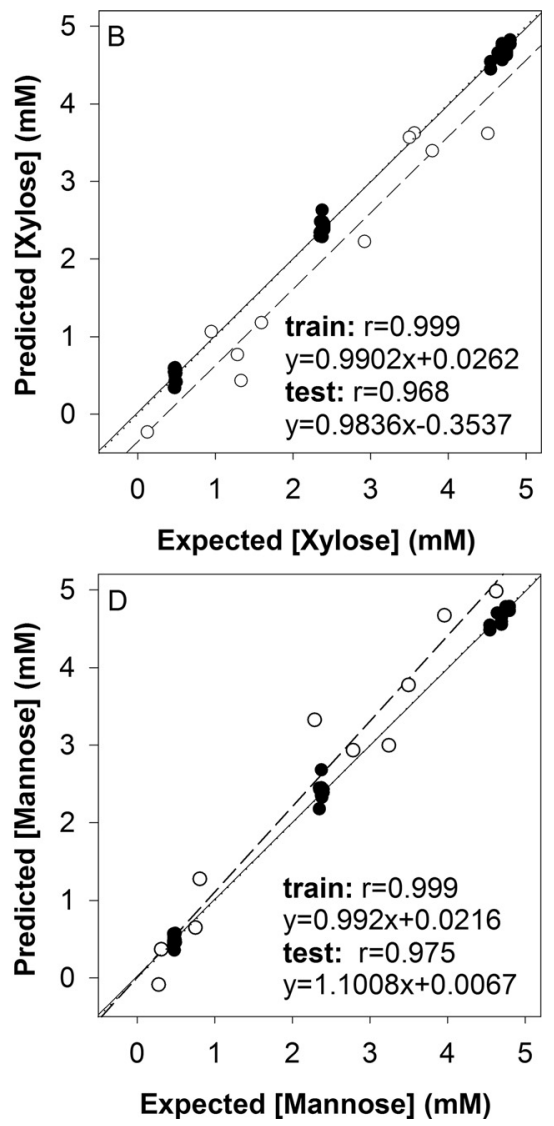

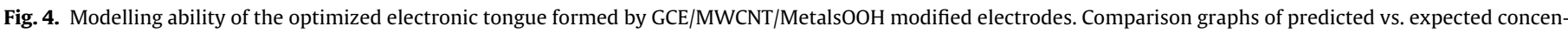

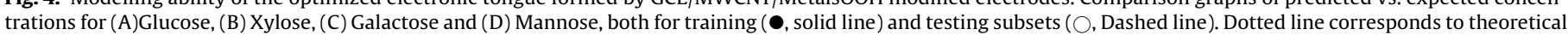
$\mathrm{Y}=\mathrm{X}$. 
10 to the testing subset with concentrations ranged from 0.5 to $5.0 \mathrm{mM}$ for each compound. These standards were first analyzed and used to build and validate the ANN model under the conditions previously described, the training and testing sets of samples were measured employing the GCE/MWCNT/MetalsOOH modified electrodes array, obtaining a complete voltammogram for each of the electrodes, and each sample. Because of the dimensionality and complexity of descriptive information generated (5 voltammograms per each sample), a double compression strategy with wavelet transform and causal index pruning was used.

Once the optimal set of coefficients was selected through Wavelet compressing and pruning the ANN final architecture was optimized. The parameters that were optimized were the 4 transfer functions employed in the hidden and output layers, the functions evaluated were tansig, logsig, satlins and purelin, and the number of neurons in the hidden layer, from 1 to 12 neurons.

In this manner 192 architectures were evaluated. The final architecture of the back-propagation ANN model had 36 input neurons, a hidden layer with 5 neurons and the tansig transfer function, an output layer with 4 neurons and the purelin transfer function.

The representation of the modeling performance of the system is illustrated in Fig. 4. This figure shows the comparison graphs of predicted vs. expected concentrations for the four carbohydrates and for training and testing subsets, that were built to check the prediction ability of the ANN model. It may be seen that a satisfactory trend was obtained, with the regression line almost indistinguishable from the theoretical one for the training subset. From these data it appears that all species demonstrate very good correlation coefficients with an $R$ value $\geq 0.99$ on the training subset. The model prediction is satisfactory for all carbohydrates and the accuracy of the obtained response is adequate. The results obtained for external test subset with much more significance than the latter, are close to the ideal values, with 0 intercepts, 1 slopes and good correlation coefficients $R$ values $\geq 0.96$.

With the aim of contrasting the goodness of these data, results were compared with those obtained from the most widely used in the chemometrics field data processing, PLS-1, with linear fittings from the comparison regression in Table S3 (supplementary material), and comparison plots, Fig. S3 (supplementary material). Both with the numeric data and with the represented plots, a slightly worst performance is evidenced from PLS treatment, from the comparison slopes more discrepant to 1.0, correlation coefficients different from 1.0, and more evidenced scatter of points in the comparison graphs. Probably the non-linear features present in the sensors result better modeled with use of the ANN than with PLS.

\section{Table 2}

Results in synthetic samples obtained from the electronic tongue formed by GCE/MWCNT/MetalsOOH modified electrodes in the analysis of Glucose, Xylose, Galactose and Mannose.

\begin{tabular}{lcc}
\hline Samples & Glucose $/ \mathrm{mmol} \mathrm{L}^{-1}$ & Glucose found $/ \mathrm{mmol} \mathrm{L}^{-1}$ \\
\hline 1 & 4.0 & 4.5 \\
2 & 2.7 & 3.2 \\
3 & 4.2 & 4.7 \\
& Xylose $/ \mathrm{mmol} \mathrm{L}^{-1}$ & Xylose found $/ \mathrm{mmol} \mathrm{L}^{-1}$ \\
1 & 3.6 & 3.6 \\
2 & 2.9 & 2.2 \\
3 & 3.5 & 3.6 \\
& Galactose $/ \mathrm{mmol} \mathrm{L}^{-1}$ & 2.6 \\
1 & 2.0 & 2.2 \\
2 & 2.0 & 1.0 \\
3 & 1.0 & Galactose found $/ \mathrm{mmol} \mathrm{L}^{-1}$ \\
& Mannose $/ \mathrm{mmol} \mathrm{L}^{-1}$ & 4.7 \\
1 & 4.0 & 4.9 \\
2 & 4.6 & 0.4 \\
3 & 0.3 & Mannose found $/ \mathrm{mmol} \mathrm{L}^{-1}$ \\
\hline
\end{tabular}

After optimizing its performance, the electronic tongue was assessed through studies on synthetic samples of sugars shown in Table 2, with three different sugar mixtures. As it can be seen results found are in good agreement with those expected.

\section{Conclusions}

In this work, the application of an electronic tongue formed by GCE/MWCNT/MetalsOOH nanoparticle modified electrodes is described for detection and quantification of carbohydrates in sugar test samples. The complex response obtained from the electronic tongue was successfully processed employing a multilayer ANN and wavelet compressed information which proved to be especially suited for building the response model. Therefore this electronic tongue has enormous potential to be applied in hydrolyzed samples from sugarcane bagasse. Merit of the proposed system is to achieve resolution of mixtures of carbohydrates, with performance equivalent to HPLC equipment, without need to use any biosensor component thus permitting more stable responses.

\section{Acknowledgements}

This work was financial supported by FAPESP (Proc. $\mathrm{n}^{\circ}$ 2011/19289-5, BEPE 2014/15557-3 and 2012/00258-5) and by Spanish ministry MINECO (Project CTQ2013-41577-P). A.Cipri was supported by Research Executive Agency (REA) of the European Union under Grant Agreement number PITN-GA-2010-264772 (ITN CHEBANA). M del Valle acknowledges support by the Catalonia program ICREA Academia. The authors are very grateful to LMA-IQ for carrying out the SEM-FEG analysis.

\section{Appendix A. Supplementary data}

Supplementary data associated with this article can be found, in the online version, at http://dx.doi.org/10.1016/j.snb.2015.08.088.

\section{References}

[1] C.A. Cardona, J.A. Quintero, I.C. Paz, Production of bioethanol from sugarcane bagasse: Status and perspectives, Bioresour. Technol. 101 (2010) 4754-4766.

[2] J.B. Sluiter, R.O. Ruiz, C.J. Scarlata, A.D. Sluiter, D.W. Templeton, Compositional analysis of lignocellulosic feedstocks. 1. Review and description of methods, J. Agric. Food Chem. 58 (2010) 9043-9053.

[3] C.R. Soccol, L.P. Vandenberghe, A.B. Medeiros, S.G. Karp, M. Buckeridge, L.P. Ramos, A.P. Pitarelo, V. Ferreira-Leitao, L.M. Gottschalk, M.A. Ferrara, E.P. da Silva Bon, L.M. de Moraes, A. Araujo Jde, F.A. Torres, Bioethanol from lignocelluloses: Status and perspectives in Brazil, Bioresour. Technol. 101 (2010) 4820-4825.

[4] Y. Sun, J. Cheng, Hydrolysis of lignocellulosic materials for ethanol production: a review, Bioresour. Technol. 83 (2002) 1-11.

[5] A. Ebringerová, Z. Hromádková, T. Heinze, Hemicellulose, Adv. Polym. Sci. 186 (2005) 1-67

[6] F.M. Girio, C. Fonseca, F. Carvalheiro, L.C. Duarte, S. Marques, R. Bogel-Lukasik, Hemicelluloses for fuel ethanol: A review, Bioresour. Technol. 101 (2010) 4775-4800.

[7] G. Wang, X. He, L. Wang, A. Gu, Y. Huang, B. Fang, B. Geng, X. Zhang, Non-enzymatic electrochemical sensing of glucose, Microchim. Acta 180 (2012) 161-186.

[8] K.E. Toghill, R.G. Compton, Electrochemical non-enzymatic glucose sensors: a perspective and an evaluation, Int. J. Electrochem. Sci. 5 (2010) 1246-1301.

[9] G. Karim-Nezhad, M. Hasanzadeh, L. Saghatforoush, N. Shadjou, S. Earshad, B. Khalilzadeh, Kinetic study of electrocatalytic oxidation of carbohydrates on cobalt hydroxide modified glassy carbon electrode, J. Brazil Chem. Soc. 20 (2009) 141-151.

[10] C. Batchelor-McAuley, G.G. Wildgoose, R.G. Compton, L. Shao, M.L.H. Green, Copper oxide nanoparticle impurities are responsible for the electroanalytical detection of glucose seen using multiwalled carbon nanotubes, Sens. Actuators B Chem. 132 (2008) 356-360.

[11] S. Zhou, X. Feng, H. Shi, J. Chen, F. Zhang, W. Song, Direct growth of vertically aligned arrays of $\mathrm{Cu}(\mathrm{OH})_{2}$ nanotubes for the electrochemical sensing of glucose, Sens. Actuators B Chem. 177 (2013) 445-452.

[12] L.A. Hutton, M. Vidotti, A.N. Patel, M.E. Newton, P.R. Unwin, J.V. Macpherson, Electrodeposition of nickel hydroxide nanoparticles on boron-doped diamond 
electrodes for oxidative electrocatalysis, J. Phys. Chem. C 115 (2011) 1649-1658

[13] J. Wang, G. Chen, M. Wang, M.P. Chatrathi, Carbon-nanotube/copper composite electrodes for capillary electrophoresis microchip detection of carbohydrates, Analyst 129 (2004) 512.

[14] C. Batchelor-McAuley, Y. Du, G.G. Wildgoose, R.G. Compton, The use of copper(II) oxide nanorod bundles for the non-enzymatic voltammetric sensing of carbohydrates and hydrogen peroxide, Sens. Actuators B Chem. 135 (2008) 230-235.

[15] Y.-G. Zhou, S. Yang, Q.-Y. Qian, X.-H. Xia, Gold nanoparticles integrated in a nanotube array for electrochemical detection of glucose, Electrochem. Commun. 11 (2009) 216-219.

[16] X.-m. Chen, Z.-j. Lin, D.-J. Chen, T.-t. Jia, Z.-m. Cai, X.-r. Wang, X. Chen, G.-n. Chen, M. Oyama, Nonenzymatic amperometric sensing of glucose by using palladium nanoparticles supported on functional carbon nanotubes, Biosens. Bioelectron. 25 (2010) 1803-1808.

[17] Z.-x. Cai, C.-c. Liu, G.-h. Wu, X.-m. Chen, X. Chen, Palladium nanoparticles deposit on multi-walled carbon nanotubes and their catalytic applications for electrooxidation of ethanol and glucose, Electrochim. Acta 112 (2013) 756-762.

[18] F. Wolfart, A.L. Lorenzen, N. Nagata, M. Vidotti, Nickel/cobalt alloys modified electrodes: Synthesis, characterization and optimization of the electrocatalytical response, Sens. Actuators B Chem. 186 (2013) 528-535.

[19] V. Ganesh, S. Farzana, S. Berchmans, Nickel hydroxide deposited indium tin oxide electrodes as electrocatalysts for direct oxidation of carbohydrates in alkaline medium, J. Power Sources 196 (2011) 9890-9899.

[20] K. Dhara, T. Ramachandran, B.G. Nair, T.G. Satheesh Babu, Single step synthesis of $\mathrm{Au}-\mathrm{CuO}$ nanoparticles decorated reduced graphene oxide for high performance disposable nonenzymatic glucose sensor, J. Electroanal. Chem. 743 (2015) 1-9.

[21] A.C. de Sa, L.L. Paim, N.R. Stradiotto, Sugars electrooxidation at glassy carbon electrode decorate with multi-walled carbon nanotubes with nickel oxy-hydroxide, Int. J. Electrochem. Soc. 9 (2014) 7746-7762.

[22] L.M.F. Gottschalk, R.A. Oliveira, E.P.d.S. Bon, Cellulases, xylanases, $\beta$-glucosidase and ferulic acid esterase produced by Trichoderma and Aspergillus act synergistically in the hydrolysis of sugarcane bagasse, Biochem. Eng. J. 51 (2010) 72-78.

[23] G. Jackson de Moraes Rocha, C. Martin, I.B. Soares, A.M. Souto Maior, H.M. Baudel, C.A. Moraes de Abreu, Dilute mixed-acid pretreatment of sugarcane bagasse for ethanol production, Biomass Bioenergy 35 (2011) 663-670.

[24] J.R.A. dos Santos, A.M. Souto-Maior, E.R. Gouveia, C. Martin, Comparison of shf and ssf processes from sugar cane bagasse for ethanol production by saccharotnyces cerevisiae, Quim Nova 33 (2010) 904-908.

[25] E.R. Gouveia, R.T. do Nascimento, A.M. Souto-Maior, G.J.D. Rocha, Validation of methodology for the chemical characterization of sugar cane bagasse, Quim Nova 32 (2009) 1500-1503.

[26] J. Gallardo, S. Alegret, R. Muñoz, L. Leija, P.Ro. Hernández, M. del Valle, Use of an electronic tongue based on all-solid-state potentiometric sensors for the quantitation of alkaline ions, Electroanalysis 17 (2005) 348-355.

[27] A. Gutés, F. Céspedes, M. del Valle, Electronic tongues in flow analysis, Anal. Chim. Acta 600 (2007) 90-96.

[28] X. Cetó, A.M. O’ Mahony, J. Wang, M. del Valle, Simultaneous identification and quantification of nitro-containing explosives by advanced chemometric data treatment of cyclic voltammetry at screen-printed electrodes, Talanta 107 (2013) 270-276.

[29] X. Cetó, J.M. Gutiérrez, L. Moreno-Barón, S. Alegret, M. del Valle, Voltammetric electronic tongue in the analysis of cava wines, Electroanalysis 23 (2011) $72-78$.

[30] M. del Valle, Electronic tongues employing electrochemical sensors, Electroanalysis (2010) 1539-1555.

[31] L. Nuñez, X. Cetó, M.I. Pividori, M.V.B. Zanoni, M. del Valle, Development and application of an electronic tongue for detection and monitoring of nitrate, nitrite and ammonium levels in waters, Microchem. J. 110 (2013) 273-279.

[32] Y. Vlasov, A. Legin, A. Rudnitskaya, C. Di Natale, A. D’Amico, Nonspecific sensor arrays ("electronic tongue") for chemical analysis of liquids (IUPAC Technical Report), Pure Appl. Chem. 77 (2005) 1965-1983.

[33] X. Cetó, A. González-Calabuig, J. Capdevila, A. Puig-Pujol, M. del Valle, Instrumental measurement of wine sensory descriptors using a voltammetric electronic tongue, Sens. Actuators B Chem. 207 (2015) 1053-1059.

[34] X. Cetó, J.M. Gutiérrez, M. Gutiérrez, F. Céspedes, J. Capdevila, S. Mínguez, C. Jiménez-Jorquera, M. del Valle, Determination of total polyphenol index in wines employing a voltammetric electronic tongue, Anal. Chim. Acta 732 (2012) 172-179.

[35] X. Cetó, J. Capdevila, A. Puig-Pujol, M. del Valle, Cava wine authentication employing a voltammetric electronic tongue, Electroanalysis 26 (2014) 1504-1512.

[36] G.Y.W. Taguchi, Introduction to off-line quality control, Central Japan Quality Control Assoc. (1979) 33-43

[37] M. del Valle, R.M. Guerrero, J.M.G. Salgado (Eds.), Wavelets: Classification, Theory and Applications, Nova Science Pub Inc, New York, US, 2011.

[38] R.A. Johnson, D.W. Wichestein, Applied multivariate statistical analysis, Pearson Education, Harlow, GB, 2007.
[39] A. Cipri, M. del Valle, Pd nanoparticles/multiwalled carbon nanotubes electrode system for voltammetric sensing of tyrosine, J. Nanosci. Nanotechnol. 14 (2014) 6692-6698.

[40] Y. Shi, R. Yang, P.K. Yuet, Easy decoration of carbon nanotubes with well dispersed gold nanoparticles and the use of the material as an electrocatalyst, Carbon 47 (2009) 1146-1151

[41] Z. Yang, J. Feng, J. Qiao, Y. Yan, Q. Yu, K. Sun, Copper oxide nanoleaves decorated multi-walled carbon nanotube as platform for glucose sensing, Anal. Methods 4 (2012) 1924.

[42] A. Salimi, H. Mamkhezri, R. Hallaj, S. Soltanian, Electrochemical detection of trace amount of arsenic(III) at glassy carbon electrode modified with cobalt oxide nanoparticles, Sens. Actuators B Chem. 129 (2008) 246-254.

[43] Q. Cheng, C. Wu, J. Chen, Y. Zhou, K. Wu, Electrochemical tuning the activity of nickel nanoparticle and application in sensitive detection of chemical oxygen demand, J. Phys. Chem. C 115 (2011) 22845-22850.

[44] N.J. Wittenberg, C.L. Haynes, Using nanoparticles to push the limits of detection. Wiley Interdisciplinary Reviews, Nanomed. Nanobiotechnol. 1 (2009) 237-254

[45] C. Welch, R. Compton, The use of nanoparticles in electroanalysis: a review, Anal. Bioanal. Chem. 384 (2006) 601-619.

[46] C.C. Hu, T.C. Wen, Voltammetric investigation of palladium oxides.2. Their formation reduction behavior during glucose-oxidation in Naoh, Electrochim. Acta 39 (1994) 2763-2771.

[47] B.K. Jena, C.R. Raj, Enzyme-free amperometric sensing of glucose by using gold nanoparticles, Chem. A Eur. J. 12 (2006) 2702-2708.

[48] M. Pasta, F. La Mantia, Y. Cui, Mechanism of glucose electrochemical oxidation on gold surface, Electrochim. Acta 55 (2010) 5561-5568.

[49] J. Yang, W.-D. Zhang, S. Gunasekaran, An amperometric non-enzymatic glucose sensor by electrodepositing copper nanocubes onto vertically well-aligned multi-walled carbon nanotube arrays, Biosens. Bioelectron. 26 (2010) 279-284.

[50] A.A. Ensafi, M.M. Abarghoui, B. Rezaei, A new non-enzymatic glucose sensor based on copper/porous silicon nanocomposite, Electrochim. Acta 123 (2014) 219-226.

[51] T.R.I. Cataldi, I.G. Casella, E. Desimoni, T. Rotunno, Cobalt-based glassy-carbon chemically modified electrode for constant-potential amperometric detection of carbohydrates in flow-injection analysis and liquid-chromatography, Anal. Chim. Acta 270 (1992) 161-171.

[52] E. Richards, C. Bessant, S. Saini, Multivariate data analysis in electroanalytical chemistry, Electroanalysis 14 (2002) 1533-1542.

\section{Biographies}

Acelino Cardoso de Sá received his degree in Chemistry in 2007, received his Master in Condensed Matter Physics at Science Materials program at the Paulista State University-UNESP working on the themes: electroanalytical, copper nitroprusside, cobalt nitropursside, 3-aminopropyl silica gel and electrodes chemically modified. Ph.D. student in Analytical Chemistry. His main research field is the biofuels (second generation ethanol) at Institute of Chemistry-UNESP, Araraquara, Brazil. Ph.D. student at the Universitat Autònoma de Barcelona working in the analysis of sugars from cane sugar bagasse using electronic tongues.

Andrea Cipri studied Chemistry at the University of Sassari, Italy. He received his Master degree in 2011. At the beginning of 2012 he joined the group of Manel del Valle at the Universitat Autònoma de Barcelona (UAB), Spain, as a Marie Curie fellow for his PhD. He is currently a PhD fellow in Manel del Valle group and his research interests include the study of nano-materials and bio-materials for sensing applications and devices.

Andreu González-Calabuig received his M.Sc. degree in Chemistry in 2013 from the Universtitat Autònoma de Barcelona, where he is at the moment completing his Ph.D. in Analytical Chemistry. His main research topics deal with the application of Electronic Tongues as a tool for security and food safety analysis.

Nelson Ramos Stradiotto graduated from the University of Sao Paulo, Brazil with a PhD degree in chemistry in 1980 for studies on "the kinetics and mechanism of tin reduction in aprotic media". He spent 2 years at The University of Southampton as a fellow researcher (1983-1984) and 2 years at The Loughborough University (1992-1994). Presently, he is a professor at the Institute of Chemistry-UNESP, Araraquara, Brazil. His research interests include Analytical Chemistry and Physical Chemistry in the specialties of Electrochemistry and Electroanalysis. The theme of current research is related to Sensors, Electrochemical Detectors coupled with chromatographic techniques and electroanalytical methods in Bioenergy, with emphasis on Biofuels, Bioproducts, Biomass and Biorefineries.

Manel del Valle received his Ph.D. in Chemistry in 1992 from the Universitat Autònoma de Barcelona, where he got a position of associate professor in Analytical Chemistry. He is a member of the Sensors \& Biosensors Group where he is a specialist for instrumentation and electrochemical sensors. He has initiated there the research lines of sensor arrays and electronic tongues. Other interests of his work are the use of impedance measurements for sensor development, biosensors and the design of automated flow systems. 